\title{
A study of meteorologically and seismically induced water level and water temperature oscillations in an estuary located on the west coast of India (Arabian Sea)
}

\author{
P. Mehra, R. G. Prabhudesai, A. Joseph, V. Kumar, Y. Agarvadekar, R. Luis, and B. Viegas \\ National Institute of Oceanography, Council of Scientific and Industrial Research (CSIR), Goa, India \\ Correspondence to: P. Mehra (pmehra@nio.org)
}

Received: 19 August 2010 - Revised: 12 May 2011 - Accepted: 11 January 2012 - Published: 21 May 2012

\begin{abstract}
The study examines the observed storm-generated sea-level oscillations (June 2007 and November 2009) along with the Sumatra geophysical tsunami (September 2007), indicating similarities in the sea-level response in the Mandovi estuary of Goa in the eastern Arabian Sea. Sea-level and surface meteorological measurements collected during storms exhibit strong synoptic disturbances leading to the coherent oscillations in the estuary with significant energy bands centred at periods of 24,45 , and $80 \mathrm{~min}$. In particular, during the sporadic atmospheric event of June 2007, the atmospheric pressure dipped by $\sim 12 \mathrm{mb}$, the wind direction stabilized to $\sim 249^{\circ}$ with peak wind speed up to $16 \mathrm{~m} \mathrm{~s}^{-1}$ and the positive sea-level surge swelled up by $\sim 40 \mathrm{~cm}$. Also, the water temperature cooled down by $\sim 4.5^{\circ} \mathrm{C}$. Approximately 3 days prior to the 12 September 2007 Sumatra earthquake, the water temperature at Verem station started exhibiting a distinctly stronger semidiurnal oscillation (with a relatively larger variance of $\sim 17.9^{\circ} \mathrm{C}^{2}$ in contrast to a lesser variance of $\sim 12{ }^{\circ} \mathrm{C}^{2}$ during the preceding normal days) and these well-defined oscillations continued to manifest for a week after the earthquake. The pre-earthquake enhanced seawater temperature oscillations observed at this tropical estuary provides an indication that routine monitoring of seawater temperature from tropical estuaries with fine temporal resolution may provide early information about impending coastal earthquakes.
\end{abstract}

\section{Introduction}

The open ocean long waves generated in response to major forcing such as undersea seismic activity, atmospheric disturbances and so forth, and approaching the coast occasionally, generate large amplitude seiches in certain regions.
Although these waves may have different sources and, therefore, different characteristics, the local topography may modify them in similar ways, thereby producing similar oscillations and sometimes even destructive consequences. The meteotsunamis are mainly associated with atmospheric gravity waves, pressure jumps, frontal passages, squalls and other types of atmospheric disturbances, which normally generate barotropic ocean waves in the open ocean and amplify them near the coast through specific resonance mechanisms (Proudman, Greenspan, shelf, harbour). Therefore, the observed sea-level oscillations near the coast are a combined effect of one or more external forcing and topographic influence. The periods of such sea-level oscillations may range from minutes to hours. The synoptic atmospheric perturbations, such as atmospheric pressure or wind patterns, generally have characteristic spatial scales of a few hundred kilometres and may have time periods larger than a few hours. The spatial and temporal scales normally associated with the large-scale synoptic perturbations $(500 \mathrm{~km},>1$ day) and the observed high-frequency sea-level variability $(50 \mathrm{~km}$, minutes) are normally not well matched. Therefore, synoptic atmospheric systems are not likely to excite directly highfrequency sea-level oscillations even if realistically they can be considered to be quite broadband (both in frequency and wave number), as they usually do not contain much energy at the scales and periods required for the excitation of seiches (Candela et al., 1999). However, synoptic atmospheric systems are known to develop instabilities that radiate energy in the form of high frequency gravity waves (Fujita, 1955; Monserrat and Thorpe, 1992). Excitation of shortperiod (minutes) sea-level oscillations near a coast by the passage of atmospheric pressure gravity waves has been observed in other places such as Nagasaki Bay in Japan, where the phenomenon is known as "Abiki" (Hibiya and Kajiura 
1982). Similar short-period (minute) oscillations of meteorological origin are observed to occur at times at some bays and estuaries and have local names such as "Rissaga" in Belearic Island, "Marubbio" in Sicily, "Milghuba" in Malta and "Seebär" in Baltic Sea. However, several authors suggested the term "meteotsunami" or "meteorological tsunami" to describe these oscillations, signifying their similarity to tsunami waves (see Rabinovich and Monserrat (1996) and Monserrat et al. (2006) for a comprehensive account on observations and nomenclature of such phenomena).

The objective of the present study is to investigate the mechanism and characteristics of the oscillation of the water body in the Mandovi estuary in the central west coast of India, due to two different sources: (1) the passage of cyclones Yemnin (June 2007) and Phyan (November 2009) and (2) geophysical tsunami (September 2007). The characteristics of these oscillations are investigated by analysing the sea-level data from a subsurface pressure-based sea-level gauge deployed at Verem in the Mandovi estuary along with surface meteorological measurements from the region. Section 2 introduces the data and equipments used, Sect. 3 presents our findings and discussion and Sect. 4 provides conclusions.

\section{Data and methods}

In the present study, time-series data from two locations are used: Verem (Goa) and Kavarratti Island (Lakshdweep Archipelago) as shown in Fig. 1a. These stations are part of an Integrated Coastal Observation Network (ICON) for real/near-real time monitoring of sea-level, sea-state and surface-meteorological data from Indian coasts and Islands (Prabhudesai et al., 2006, 2010; Joseph 2011). At Dona Paula, Goa, the automatic weather station (AWS) is installed on the terrace of the National Institute of Oceanography (NIO) at a height of $\sim 48 \mathrm{~m}$ a.s.l., and at Kavaratti the AWS is installed on top of the sea-level station building at a height of $\sim 10 \mathrm{~m}$ a.s.l. (sensor evaluation described by Mehra et al., 2005). Sea levels were measured (see Fig. 1 and Table 1) using real/near-real time reporting subsurface pressure-based sea-level gauges deployed at Verem and Kavaratti. The pressure transducer (Honeywell Inc.) incorporating silicon piezoresistive technology used in the pressure tide gauge has been evaluated by Vijaykumar et al. (2005) and Mehra et al. (2008) for oceanographic and limnological measurements. The horizontal distance between the sea-level gauge and the weather station locations at Goa is $\sim 5 \mathrm{~km}$. The observed parameters (Table 1) and the observation periods covered under different events are as follows:

- Event 1 (E1): 23-25 June 2007; passage of cyclonic storm Yemnin.

- Event 2 (E2): 12-14 September 2007; occurrence of Sumatra tsunami.
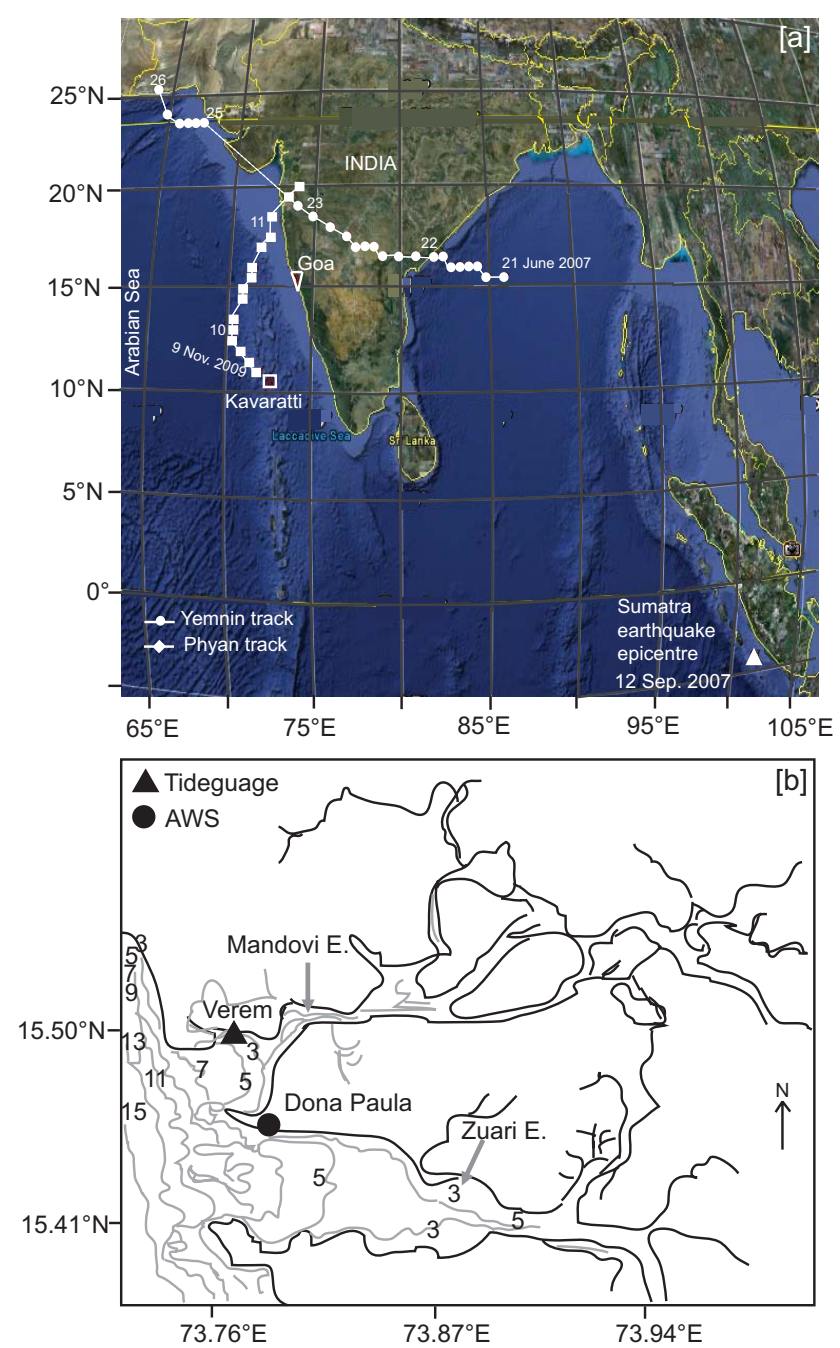

Fig. 1. The study region at the west coast of India in the Arabian Sea (a) along with the cyclone tracks of Yemnin and Phyan (www.imd.gov.in) and also indicting the 12 September 2007 Sumatra earthquake epicentre; (b) the locations of automatic weather station (AWS) and tide gauge station in Mandovi estuary region (b is adapted from Fig. 1, Sundar and Shetye, 2005).

- Event 3 (E3): 9-12 November 2009; passage of cyclonic storm Phyan.

The relevant surface meteorological parameters (wind and air pressure) are sampled every $10 \mathrm{~s}$ and averaged over 10 min duration to generate the data series at 10 -min interval. The sea-level data measured using sub-surface pressure gauge are sampled at $2 \mathrm{~Hz}$ frequency for 5-min duration (600 samples), averaged and then recorded in the datalogger at 5-min interval. The sea-level data is corrected for the atmospheric pressure variations and then detided using the TASK-tidal analysis and prediction program (Bell et al., 2000) to obtain sea level residuals (SLR). The atmospheric pressure data measured at $10 \mathrm{~min}$ interval were interpolated 
Table 1. Summary of observations.

\begin{tabular}{|c|c|c|c|c|}
\hline $\begin{array}{l}\text { Measurement } \\
\text { station }\end{array}$ & Measured variable & Event & System & $\begin{array}{l}\text { Depth/ } \\
\text { Height } \\
(\mathrm{m})^{*}\end{array}$ \\
\hline Verem, Goa & Sea level, water temperature & $\mathrm{E} 1, \mathrm{E} 2$, and $\mathrm{E} 3$ & $\begin{array}{l}\text { Subsurface pressure gauge and } \\
\text { temperature sensor }\end{array}$ & -1.0 \\
\hline Dona Paula, Goa & Wind and air pressure & $\mathrm{E} 1$ and $\mathrm{E} 3$ & AWS & 48 \\
\hline $\begin{array}{l}\text { Kavaratti, } \\
\text { Lakshdweep } \\
\text { archipelago }\end{array}$ & $\begin{array}{l}\text { Sea level, water temperature } \\
\text { Wind and air pressure }\end{array}$ & $\begin{array}{l}\text { E1 } \\
\text { E1 }\end{array}$ & $\begin{array}{l}\text { Subsurface pressure gauge } \\
\text { AWS }\end{array}$ & $\begin{array}{l}-1.0 \\
10\end{array}$ \\
\hline
\end{tabular}

* For the pressure gauge and AWS, the depth and height are given relative to chart datum and mean sea level, respectively.

for 5 min interval only for barometric correction of sea level measurements. The spectra of SLR and the atmospheric pressure during the event as well as that of the background signal are obtained by applying the method suggested by Rabinovich (1997).

\section{Results and discussion}

During the year 2007, the Arabian Sea experienced three atmospheric disturbances and the arrival of Sumatra tsunami waves. In particular, two meteorological events occurred during June 2007. The first, named "Gonu", originated at $15.0^{\circ} \mathrm{N}, 68.0^{\circ} \mathrm{E}$ in the Arabian Sea on 1 June 2007 and crossed the northeast Oman coast near Muscat during 02:00-03:00 UTC on 6 June and moved further north to $25.5^{\circ} \mathrm{N}, 58.5^{\circ} \mathrm{E}$ by 7 June. During the course of cyclone movement, the estimated central pressure (ECP) dipped to $920 \mathrm{hPa}$ and the corresponding sustainable surface winds peaked to 127 knots about $20^{\circ} \mathrm{N}, 64^{\circ} \mathrm{E}$ on 4 June during 15:00-18:00 UTC. Gonu was too far away to generate any noticeable influence over the sea level at the present study region. Another cyclone (E1) named "Yemnin" originated on 21 June 2007 at 03:00 UTC in the Bay of Bengal (BoB) about $15.5^{\circ} \mathrm{N}, 86.0^{\circ} \mathrm{E}$, which crossed north Andhra Pradesh (Machilipatanam) during 01:00-03:00 UTC on 22 June. There was a well-marked low pressure over north Konkan region and its neighborhood $\left(\sim 19.0^{\circ} \mathrm{N}, 74.0^{\circ} \mathrm{E}\right)$ and this then moved toward the west coast of Pakistan (near $64.0^{\circ} \mathrm{E}$ ) as a cyclonic storm by 26 June 2007 as recorded by India Meteorological Department (IMD, www.imd.gov.in). Then, we observed the tsunami (E2) at Goa (west coast of India) and Kavaratti Island lagoon (Lakshadweep archipelago) in the Arabian Sea, caused by the 12 September 2007 Sumatra earthquake. The tsunami arrived at Kavaratti Island and Goa after travelling nearly $5 \mathrm{~h}$ : $15 \mathrm{~min}$ and $8 \mathrm{~h}$, respectively, from the source region in Sunda trench (Prabhudesai et al., 2008). Manifestation of the September-2007 Sumatra tsunami in the Indian Ocean has been reported also by
Pattiaratchi and Wijeratne (2009). Another tropical cyclonic storm (E3) "Phyan", which developed in the south-eastern Arabian Sea and swept northward along the eastern Arabian Sea during 9-12 November 2009 until its landfall at the northwest coast of India, is also examined to study the response of the coastal waters at Verem, Goa (Fig. 1).

\subsection{Responses of sea level to cyclones "Yemnin" and "Phyan" and the Sumatra Tsunami (2007)}

The responses of sea level to cyclones "Yemnin" and "Phyan" were manifested as storm surges at the study sites as indicated in Fig. 2 and Table 2. An approximate 40-day sample of winds, atmospheric pressure, water temperature and sea-level residual are shown in Fig. 2 from Verem (during E1 and E3) and Kavaratti (during E1). The large scale extent of E1 is evident in wind and atmospheric pressure measurements at Verem, and Kavaratti Island; the latter being $\sim 550 \mathrm{~km}$ away down south of the former (Fig. 1). Almost similar meteorological conditions exist at Verem and Kavaratti (Fig. 2 and Table 2). During E1 (Julian days 172-176, 2007, Fig. 2a.1 and b.1) the wind energy is $\sim 9.4$ (11.2) $\mathrm{m}^{2} \mathrm{~s}^{-2}$ with amplitude peaking up to $16.6(16.8) \mathrm{m} \mathrm{s}^{-1}$ at Verem (Kavaratti). The wind directions at Verem and Kavaratti stations stabilized (Fig. 2 a. 2 and b.2) to $\sim 249^{\circ}$ and $239^{\circ}$, respectively, with respect to north during and after Yemnin (Julian days 174-198, 2007 (Table 2). The atmospheric pressure (Fig. 2a.3 and b.3) shows a variance of $\sim 18.0$ (10.8) $\mathrm{mb}^{2}$ and reports fall of $\sim 10.8$ (6.9) mb during E1 (Julian days 172-180, 2007) at Verem (Kavaratti). However, there is a difference in the water temperatures observed at these two stations. Whereas the water temperature at Verem dropped by $\sim 4.5^{\circ} \mathrm{C}$, that at Kavaratti did not exhibit any noticeable drop. The observed selective water temperature drop at Verem is due to the influx of cooler rain-induced fresh water (rainfall of $\sim 555 \mathrm{~mm}$ in the study region during Julian days 170-180, 2007) discharged into this region from the Mandovi and Zuari estuaries. Kavaratti being an open ocean station, such cooler water discharge was absent. The 

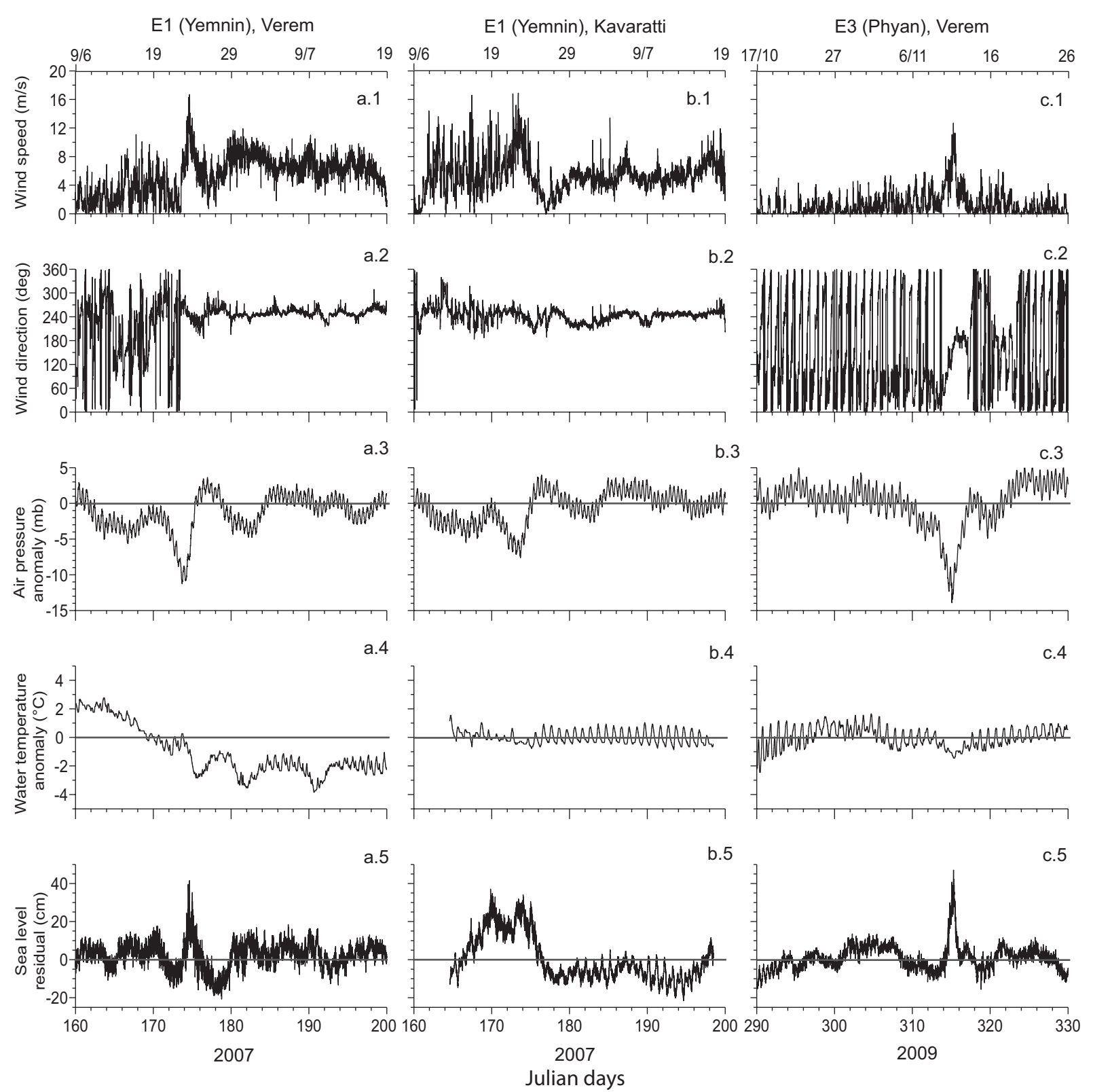

Fig. 2. Sea level and surface meteorological parameters at Goa during the episodic events. (a 1-5) wind speed, wind direction, atmospheric pressure anomaly, water temperature anomaly and sea-level residual during the atmospheric disturbance event E1 in June 2007 (named Yemnin) at Verem. (b 1-5) Variables same as in (a) at Kavaratti Island region during E1, and (c 1-5) Variables same as in (a) during the atmospheric disturbance E3 (named Phyan) in November 2009 at Verem.

sea-level responses at Verem and Kavaratti were manifested in terms of positive surges up to $\sim 40 \mathrm{~cm}$ and $36 \mathrm{~cm}$, respectively.

Similar meteorological conditions occurred at Verem during Phyan (E3, Julian days 310-320, 2009, Fig. 2c). The wind speed during Julian days 314-316 peaked up to $12.6 \mathrm{~m} \mathrm{~s}^{-1}$ and the wind direction during this period shifted from $54^{\circ}$ to $192^{\circ}$ with respect to north. The atmospheric pressure dipped by $\sim 12.9 \mathrm{mb}$ and the water temperature dropped by $\sim 1^{\circ} \mathrm{C}$. The sea level exhibited a positive surge up to $\sim 47 \mathrm{~cm}$ (Table 2). Detailed study in respect of the response of the coastal regions of eastern Arabian Sea (AS) and Kavaratti Island lagoon in the AS to the tropical cyclonic storm "Phyan" during 9-12 November 2009 until its landfall at the northwest coast of India is reported by Joseph et al. (2011).

Response of the sea (sea level and water temperature) at Verem station to the September 2007 Sumatra tsunami (E2) is shown in Fig. 3. Unlike a positive surge observed in the case of the episodic meteorological conditions, the 
Table 2. Meteorological and sea level observations at Verem and Kavaratti.

\begin{tabular}{|c|c|c|c|c|}
\hline $\mathrm{SN}$ & Variable & E1, Verem & E1, Kavaratti & E3, Verem \\
\hline 1 & Maximum wind speed $\left(\mathrm{m} \mathrm{s}^{-1}\right)$ & 16.6 & 16.8 & 12.5 \\
\hline 2 & Wind direction $\left(^{\circ}\right)$ & $249^{*}$ & $239^{*}$ & 185 \\
\hline 3 & Atmospheric pressure drop (mb) & 10.8 & 6.9 & 13.5 \\
\hline 4 & Water temperature drop $\left({ }^{\circ} \mathrm{C}\right)$ & 4.5 & - & 1 \\
\hline 5 & Sea level residual $(\mathrm{cm})$ & 40 & 36 & 47 \\
\hline 6 & Atmospheric pressure fall time from maximum to minimum $(\mathrm{h})$ & 79.2 & 88.8 & 64.8 \\
\hline 7 & Atmospheric pressure rise time from minimum to maximum (h) & 76.8 & 64.8 & 55.2 \\
\hline 8 & Surge rise time from minimum to maximum (h) & 45.6 & 144.0 & 43.2 \\
\hline 9 & Surge fall time from maximum to minimum (h) & 81.6 & 168.0 & 84.0 \\
\hline
\end{tabular}

* The wind direction, with respect to north, stabilized during and after cyclone Yemnin (EI) at Verem and Kavaratti stations (Julian days 174-198, 2007).

September 2007 Sumatra tsunami at Verem (Prabhudesai et al., 2008) caused oscillations of up to approximately $\pm 15 \mathrm{~cm}$ in sea-level residuals (Fig. 3a). The response of the sea at Verem station to the tsunami waves is also clearly manifested in the water temperature, which shows oscillations during E2 (Julian days 250-258) with a relatively larger variance of $\sim 17.9^{\circ} \mathrm{C}^{2}$ in contrast to a lesser variance of $\sim 12{ }^{\circ} \mathrm{C}^{2}$ during normal days just before the event (Julian days $246-$ 248). Some aspects related to the observed pre- and postearthquake seawater temperature anomaly are examined in Sect. 3.5.

\subsection{Non-resonant character of Kavaratti Island lagoon}

Kavaratti Island's lagoon is an open sea station. Based on high-pass filtered (time period $<2 \mathrm{~h}$ ) sea-level residuals (SLR) obtained using a 5th order Butterworth filter, the amplitude of high-frequency oscillations observed at Kavaratti lagoon in response to the cyclonic storm "Yemnin" was approximately $\pm 10 \mathrm{~cm}$ during E1 (Fig. 4a). The event spectrum during E1 at Kavaratti and the respective background spectrum for sea level residual (SLR) and atmospheric pressure are indicated in Fig. 4b and c, respectively. The spectrum of data series was obtained using the "pwelch" function from Matlab with the following parameters: sampling frequency: 0.2 (0.1) cpm for SLR (atmospheric pressure); Hamming window of 256 data points with $50 \%$ overlap; length of the FFT with the integer $\mathrm{nfft}=256$. The background spectrum of SLR for Kavaratti station is over the duration 1 September-9 October 2007. The background spectrum of atmospheric pressure in respect of this station is over the duration 29 June-28 July 2007 . The background spectra provide a good estimate of the topographic response for every site where the natural oscillations are not subdued by the energetic characteristics of the forcing.

It is clearly seen from Fig. $4 \mathrm{~b}$ that at Kavaratti lagoon both background and event spectra are "blue" (i.e., the energy at higher frequencies is going up). This could probably be associated with high-frequency infragravity (IG) waves generated by nonlinear interaction of wind waves and swell at this site (A. B. Rabinovich, Russian Academy of Sciences, private communication, 2011). There are no prominent spectral peaks and, hence, no natural oscillations. The oscillations seen in Fig. 4a appears to have a characteristic of stormgenerated broad-frequency signal. In any case, there was no visible seiches at this site (i.e., natural oscillations), which are indicated by prominent spectral peaks. The non-resonant character of Kavaratti Island lagoon was noticed also during cyclonic storm "Phyan", in which despite intense wind forcing, the surge at this lagoon was insignificantly weak due to the combined effect of the absence of resonant amplification and lack of river water discharge into the lagoon (Joseph et al., 2011).

\subsection{Harbour resonance}

The swing of the high-pass filtered oscillations (5th order Butterworth filter as mentioned in Sect. 3.2) observed at Verem station is approximately $\pm 15 \mathrm{~cm}$ during E1 (Fig. 5a). Also during E3 the SLR oscillations remained $\sim \pm 10 \mathrm{~cm}$ at Verem (Fig. 5c). However, there is strong similarity between the atmospherically generated "meteotsunami" and seismically generated geophysical tsunami (Fig. 5a and b). Kavaratti data is excluded in the present study (i.e., harbour resonance) because it is an open sea station, not having the resonance features of a harbour.

The event spectra estimated (see Sect. 3.2 for the method used) for Verem station during E1 (Yemnin), E2 (September 2007 Sumatra tsunami) and E3 (Phyan) and the respective background spectra for sea-level residual (SLR) and atmospheric pressure anomaly are as indicated in Figs. 6 and 7, respectively. The background spectrum of SLR in respect of Verem station is the average of spectra over 10-30 October, 10-30 November and 8-31 December of 2007. The background spectrum of atmospheric pressure with respect to this station is over the duration 1 January-31 March 2007.

The background spectra may differ if the response of the estuary is sensitive to the characteristic of forcing conditions, 

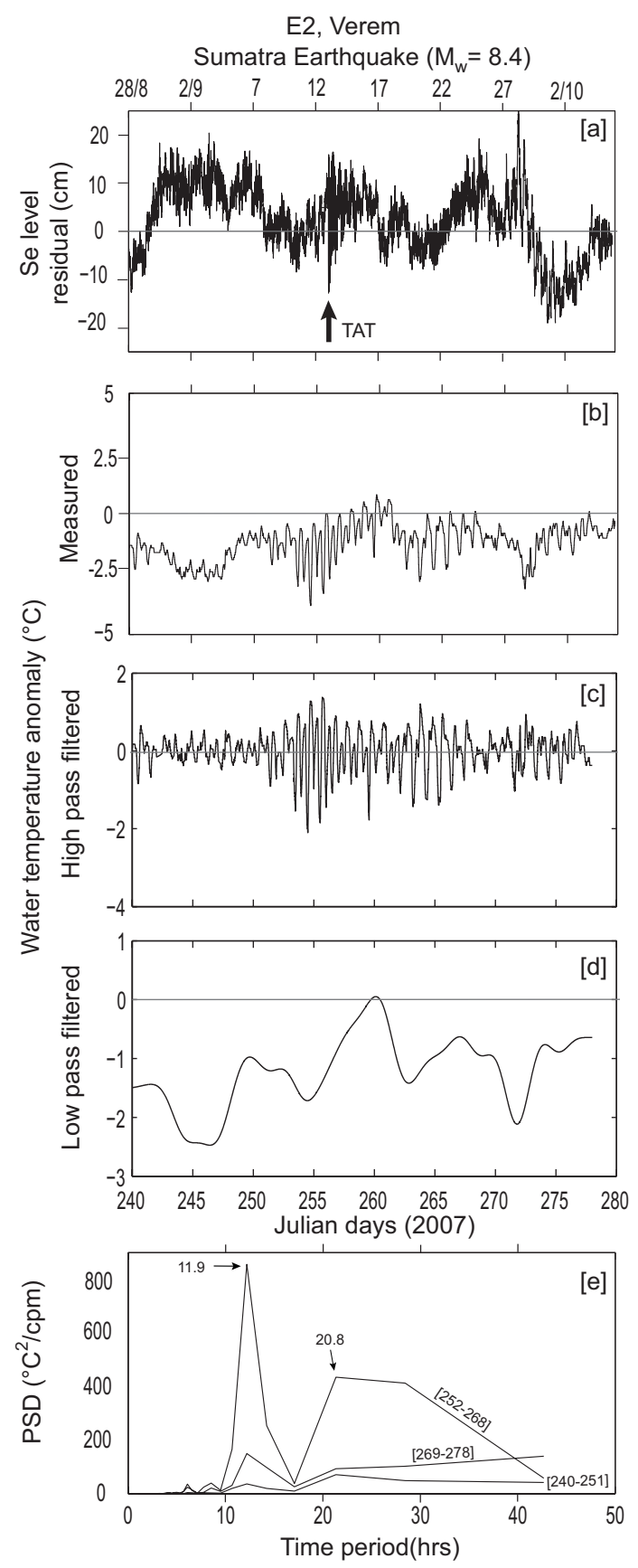

Fig. 3. Sea water parameters observed at Verem, Goa in response to the episodic event E2 of 12 September 2007 due to Sumatra earthquake $\left(M_{\mathrm{W}}=8.4\right)$. (a) sea-level residual $(\mathrm{cm})$, (b) measured water temperature anomaly $\left({ }^{\circ} \mathrm{C}\right)$, (c) high pass filtered water temperature anomaly $\left({ }^{\circ} \mathrm{C}\right)$, (d) low pass filtered water temperature anomaly $\left({ }^{\circ} \mathrm{C}\right)$ and (e) spectrum of measured water temperature anomaly before (Julian days 240-251), during (Julian days 252-268) and after (Julian days 269-278) the tsunami arrival time (TAT) at Verem. The TAT at Goa was 00:45 IST on 13 September 2007. The number associated with significant peaks is time period in hours.
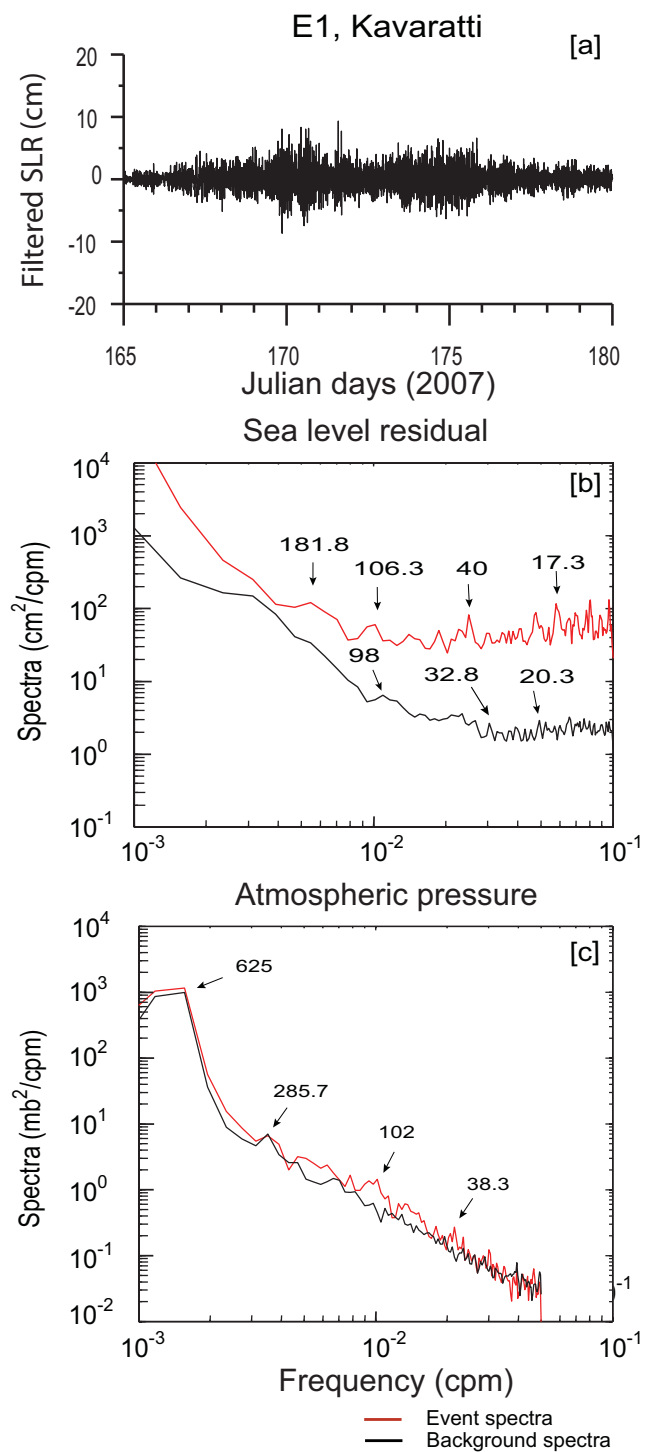

Fig. 4. Characteristics of sea-level residual (SLR) and atmospheric pressure at Kavaratti Island lagoon region during event E1 (a) time series of high pass filtered SLR (period $<2 \mathrm{~h}$ ), (b) spectrum of SLR over 8 days (Julian days 169-176; $N=2304$ ) along with background spectrum (black) and (c) spectrum of atmospheric pressure anomaly over 8 days (Julian days $169-176 ; N=1152$ ) along with background spectrum (black). The number associated with significant peaks is time period in minutes.

such as angle of incidence of the ocean waves, and may oscillate differently under varying conditions. However, the background spectra at Verem are event independent, although the "event" (atmospheric disturbance or geophysical tsunami) spectra are more energetic (Fig. 6a, b and c). On the contrary, the spectra of different sites have significant differences at high frequencies as seen at Kavaratti (Fig. 4b), indicating the influence of local topography. 


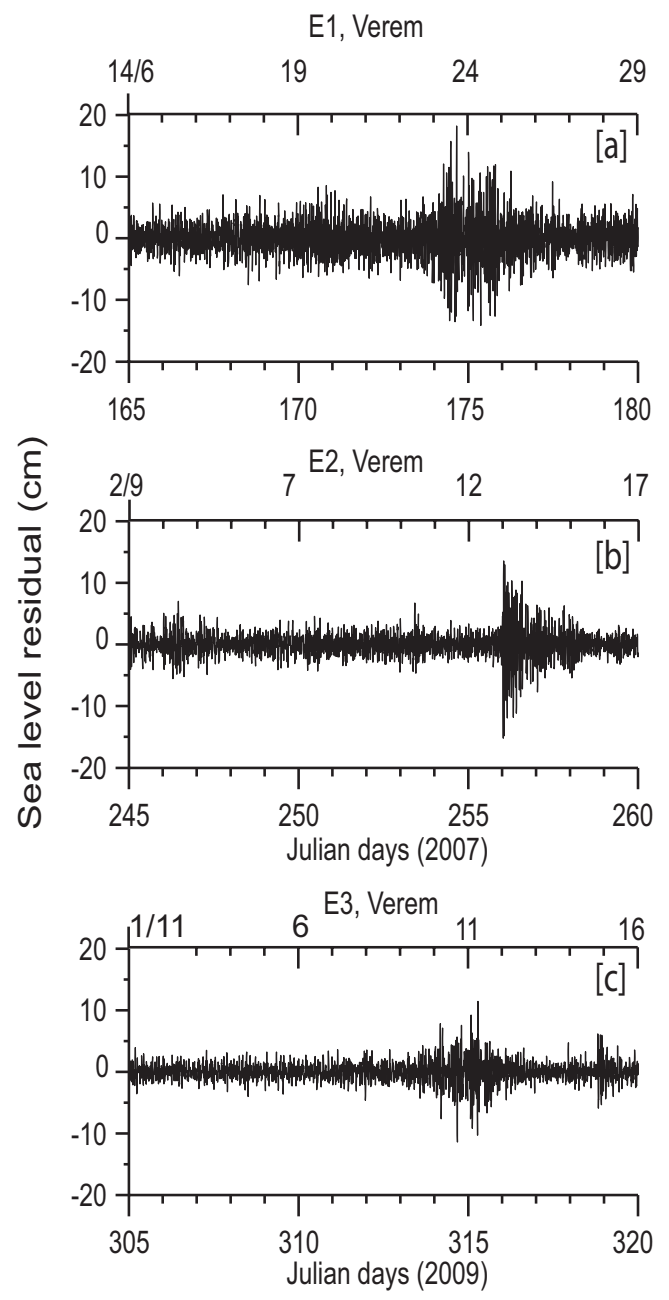

Fig. 5. Time-series of two-weeks long, high-pass filtered (period $<2 \mathrm{~h}$ ) sea-level residual at Verem during different episodic events (a) E1, (b) E2 and (c) E3. The X-axis represents Julian days of the respective year.

The Mandovi estuary, where the pressure gauge at Verem station is located, is wider $\sim 4 \mathrm{~km}$ at the mouth (also known as Aguada Bay) and the $\sim 4 \mathrm{~km}$ long stretch of the bay is marginally deeper than the rest of the estuarine channel, the average depth in the bay being about $5 \mathrm{~m}$. Then the channel narrows considerably from the bay for another $\sim 6 \mathrm{~km}$ stretch (750 $\mathrm{m}$ wide and $5 \mathrm{~m}$ deep; Shetye et al., 2007). Thus, in the case of partially enclosed basins such as gulfs, bays, fjords, inlets, ports and harbours, a specific type of seiche motion occurs known as harbour oscillation (coastal seiche), mainly generated by the long waves entering through the open boundary from the open sea. In a simple case of a narrow rectangular bay with uniform depth, the lowest mode known as Helmholts mode of oscillations normally dominate (Rabinovich, 2009) and is estimated as:

$T_{n}=\frac{4 L}{(2 n+1) \sqrt{g H}}$, for mode $n=0,1,2,3 \ldots \ldots \ldots$
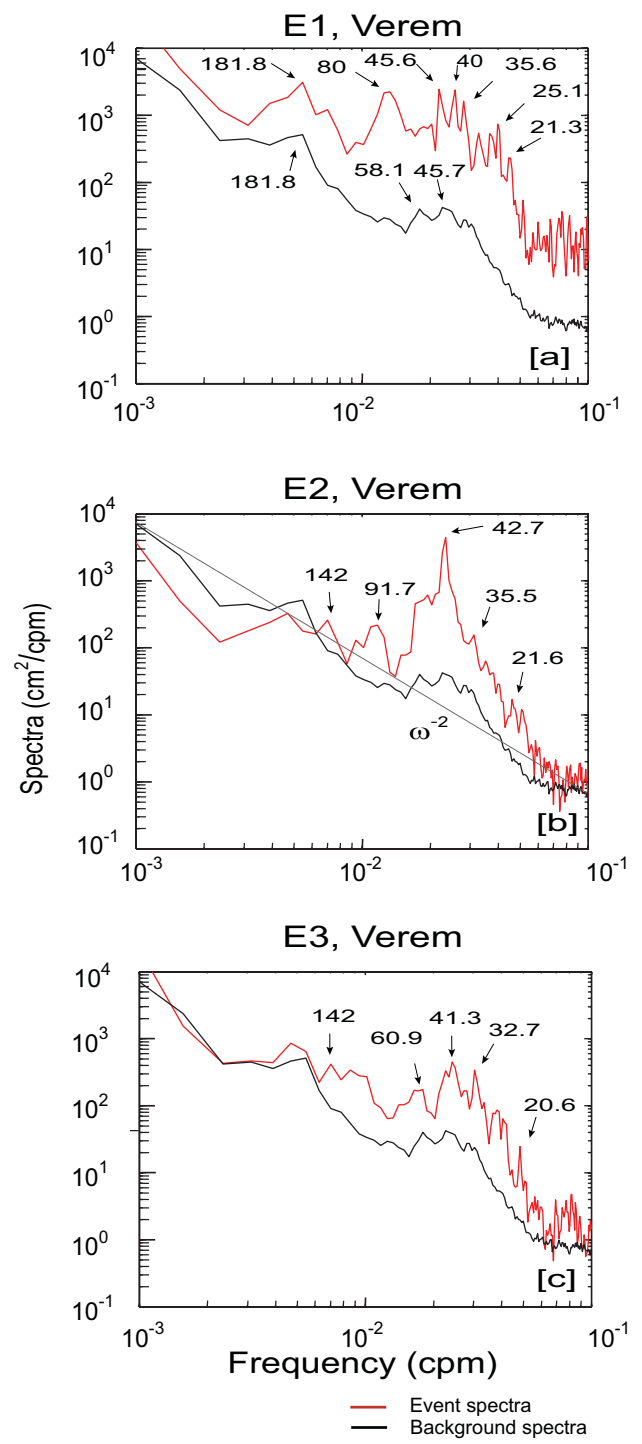

Fig. 6. Sea level residual (SLR) spectra at Verem during different events (red) along with the corresponding background spectra (black) (a) E1 over 3 days (Julian days 174-176, $N=864$ ), (b) E2 over 3 days (Julian days 255-257, $N=864$ ) and (c) E3 over 4 days (Julian days $313-316, N=1152$ ). $N$ represents the number of data samples used in estimating the spectra. The number associated with significant peaks is time period in minutes.

Thus, a rough estimate of the fundamental (Helmholtz) mode could be obtained assuming the above dimensions of the Aguada bay. The fundamental period $\left(T_{0}\right)$ of oscillation $\left(T_{0}=\frac{4 L}{\sqrt{g H}}\right)$ is $\sim 38 \mathrm{~min}$, where $L(m)$ is the length of the bay, $H(m)$ is the mean water depth and $g\left(\mathrm{~m} \mathrm{~s}^{-2}\right)$ is acceleration due to gravity.

The spectrum during E1 (Fig. 6a) shows major peaks at 80 , 45.6, 40, 35.6 and 21.3 min. During E3, the major peaks are found at 41.3, 32.7 and 20.6 (Fig. 6c). During the September 2007 Sumatra tsunami (E2) the major spectral peaks are 

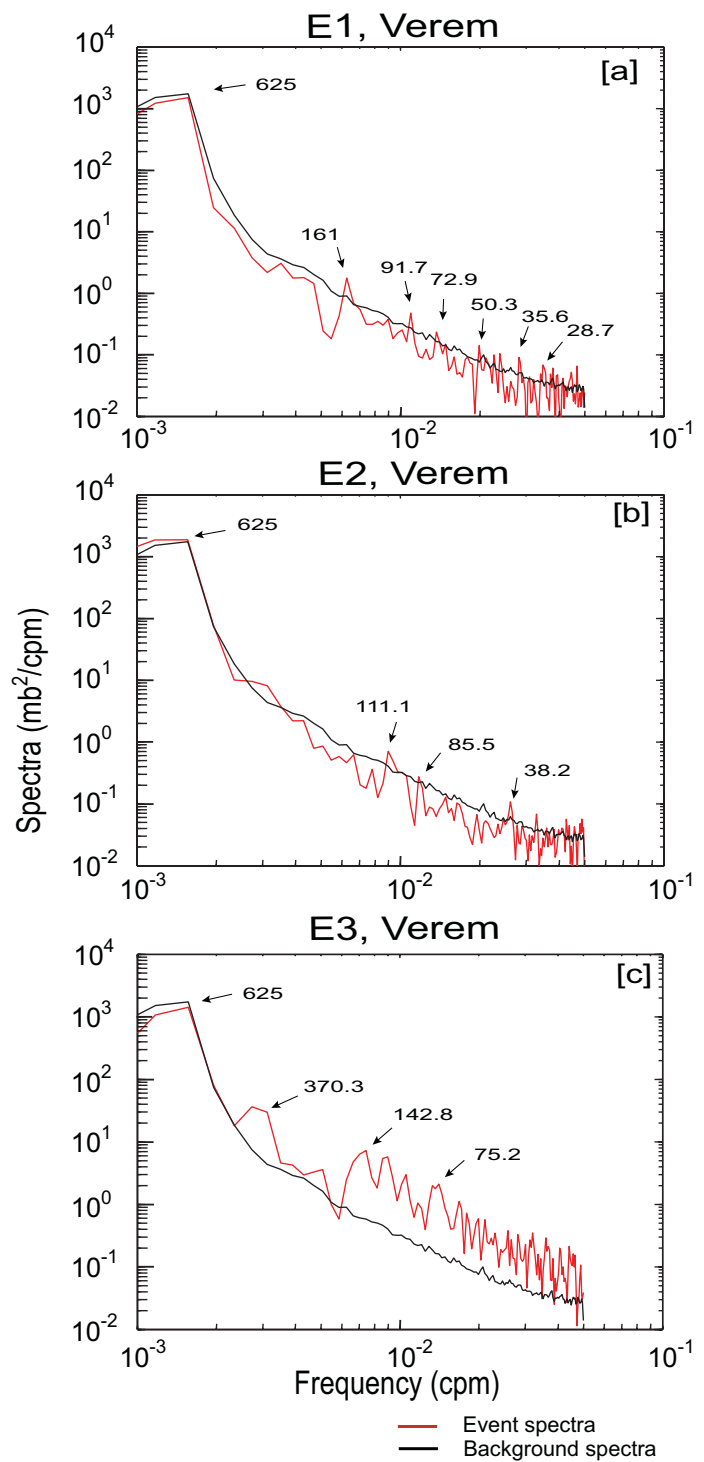

Fig. 7. Atmospheric pressure anomaly spectra during different events (red) along with the corresponding background spectra (black) at Verem (a) E1 over 3 days (Julian days 174-176, $N=432$ ) (b) E2 over 3 days (Julian days 255-257, $N=432$ ) and (c) E3 over 4 days (Julian days 313-316, $N=576$ ). $N$ represents the number of data samples used in estimating the spectra. The number associated with significant peaks is time period in minutes.

at $91.7,42.7,35.5$ and $21.6 \mathrm{~min}$ (Fig. 6b). The fundamental time period estimated using Eq. (1) is valid for a simple, narrow and long rectangular basin with constant depth, while the Aguada bay (as shown in Fig. 1b) is much more complex. It is probable that the specific period of $\sim 41.3 \mathrm{~min}$ (average of 40.0, 41.3 and $42.7 \mathrm{~min}$ ), as evident in Fig. 6 (a, b and c) is associated with the fundamental bay period (Helmholtz mode), which is in broad agreement with the theoretically estimated value of $38 \mathrm{~min}$.

\subsection{Transfer function for atmospherically generated oscillations}

The spectral ratio between the event (geophysical tsunami or atmospheric disturbance) and the respective background spectrum provides information on the external source (Fig. 8). The method to separate out the tsunami source and the topographic effects, as explained by Rabinovich (1997) and also revised and applied to atmospherically generated seiches by Monserrat et al. (1998), is briefly outlined below:

Assuming the instrumental noise is negligible, the observed spectrum $S_{\mathrm{OBS}}(\omega)$ may be considered as the sum of the energy associated with the event $S_{\mathrm{E}}(\omega)$ (tsunami or atmospheric disturbance) and the energy of the background oscillation $S_{\mathrm{B}}(\omega)$ as:

$S_{\mathrm{OBS}}(\omega)=S_{\mathrm{E}}(\omega)+S_{\mathrm{B}}(\omega)$,

If we assume that topographic response $W(\omega)$ remains unchanged for both the event and background spectra (this may not be true and should be confirmed posteriori) then:

$S_{\mathrm{E}}(\omega)=W(\omega) E_{\mathrm{E}}(\omega)$,

$S_{\mathrm{B}}(\omega)=W(\omega) E_{\mathrm{B}}(\omega)$,

where $E_{\mathrm{E}}(\omega)$ and $E_{\mathrm{B}}(\omega)$ represent the external forcing during the event and the background conditions, respectively. The spectral ratio between the event and the background signals is then:

$R(\omega)=\frac{S_{\mathrm{OBS}}(\omega)}{S_{\mathrm{B}}(\omega)}=\frac{E_{\mathrm{E}}(\omega)}{E_{\mathrm{B}}(\omega)}+1$,

Assuming that the initial sea level variations in the open sea are forced by the atmospheric pressure, we may express $E_{\mathrm{E}}(\omega)$ as:

$E_{\mathrm{E}}(\omega)=T(\omega) P_{\mathrm{o}}(\omega)$,

where $P_{\mathrm{o}}(\omega)$ is the open ocean atmospheric pressure spectrum and $T(\omega)$ is the transfer function between the atmosphere and the ocean. The transfer function depends on the direction and the phase speed of the atmospheric waves, bathymetry of the generation region, etc. In most cases, the open ocean spectrum may not be available and if the atmospheric wave is coherent over a large area, then the coastal atmosphere pressure $P_{\mathrm{C}}(\omega)$ may be used in Eq. (6). Rearranging Eqs. (3), (4) and (5) we get:

$T(\omega)=(R(\omega)-1) \frac{E_{\mathrm{B}}(\omega)}{P_{\mathrm{o}}(\omega)}$,

The long-term bottom pressure measurements in the Pacific indicate that the background open-ocean spectrum $E_{\mathrm{B}}(\omega)$ is virtually universal (Kulikov et al., 1983) and can be defined as: 

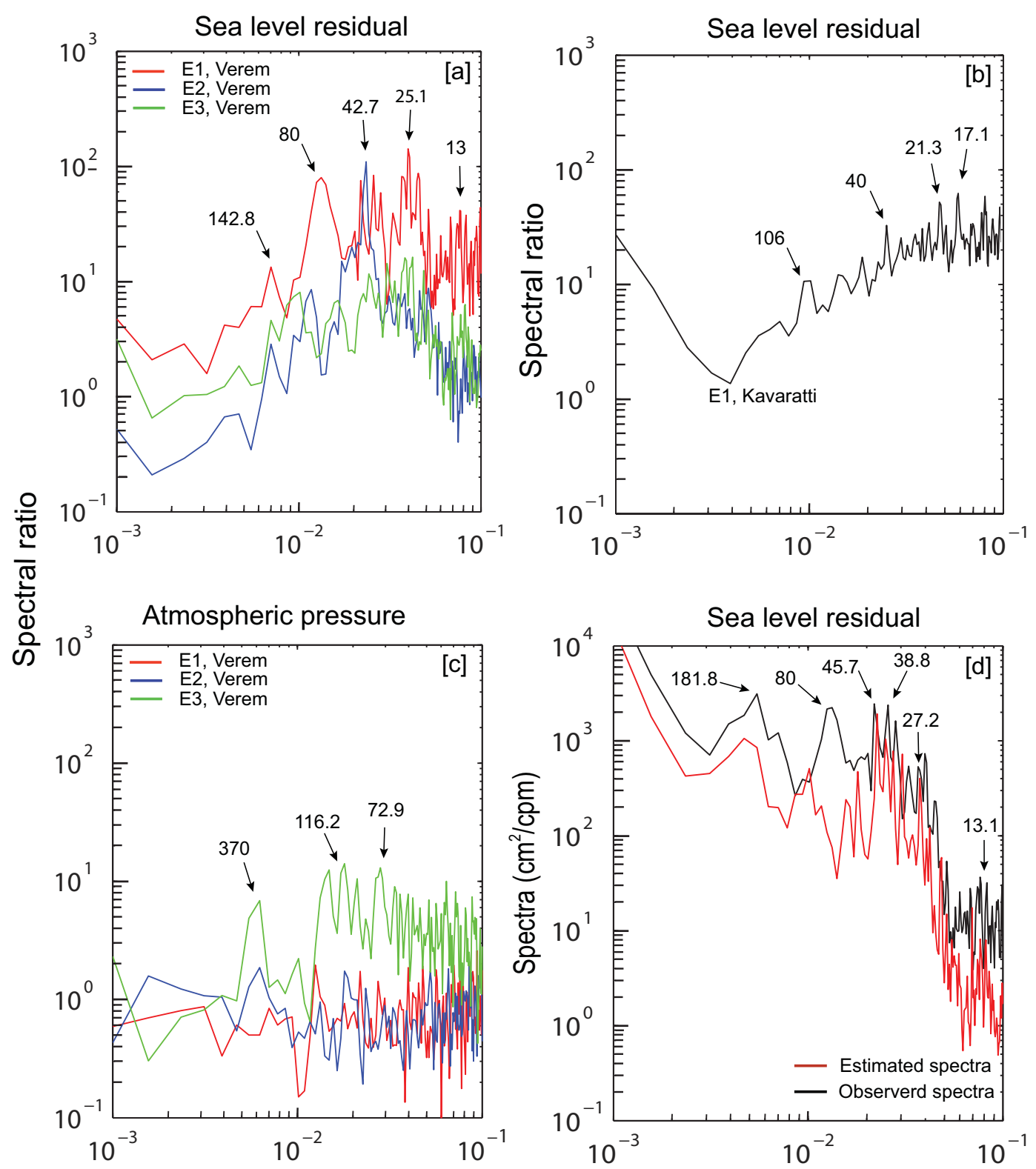

Frequency (cpm)

Fig. 8. Spectral ratio (i.e., ratio of spectra during the event to that of the respective background oscillations) of (a) SLR at Verem (Goa) during the events E1, E2 and E3, (b) SLR at Kavarrati during event E1, (c) atmospheric pressure anomaly at Verem (Goa) during the events E1, E2 and E3. (d) Observed (black) and the computed (red) spectra of SLR at Verem for event E1. The computed SLR spectrum is obtained using atmospheric pressure during E3 based on Eq. (9). The numbers associated with significant peaks are time period in minutes.

$E_{\mathrm{B}}(\omega)=C \omega^{-2}$,

where $C$ is a constant at a given depth, but increasing with the decreasing water depth and depending on the atmospheric activity. The background spectrum at Verem station is used to estimate the value of $\mathrm{C}$ (Eq. 8 ) $\sim 7 \times 10^{3} \mathrm{~cm}^{2} \mathrm{cpm}$ (straight line with a -2 slope as shown in Fig. 6b), in comparison with the values $\mathrm{C}=10^{-3}-10^{-4} \mathrm{~cm}^{2} \mathrm{cpm}$ found by Rabinovich (1997) for the open ocean.
The spectral ratio may be considered as an estimate of the energy of the external incoming waves during an event. The spectral ratio of SLR for the three events at Verem station during atmospheric disturbances (E1 and E3) and September 2007 Sumatra tsunami (E2) are shown in Fig. 8a. The spectral ratio of event to background for SLR at Verem during E1 (Yemnin, red line) is more energetic than during E3 (Phyan, green line) with similar peaks at time periods 22 and $13 \mathrm{~min}$, respectively, and similar significant gains are also observed at 
Kavaratti (Fig. 8b), which appear to have atmospheric disturbance as its forcing because the same is absent for the event E2 (tsunami, blue). However, the spectral ratio peaks around time period $\sim 42.7 \mathrm{~min}$ is present for all the three events at Verem, which also appears to be its Helmhotz period. Another prominent spectral ratio at Verem during E1 is at time period $\sim 80 \mathrm{~min}$, which is absent for other events. The spectral ratio of event to background for atmospheric pressure is shown in Fig. 8c. During E3 at Verem (Phyan, green), the spectral ratio is high compared to the other two events up to time periods $\sim 116 \mathrm{~min}$. If the spectral ratios are independent of measurement location (topography) and entirely related to the forcing, then the spectral ratios may not be similar at a given location for different events as observed during E1, E2 and E3 at Verem (Fig. 8a). Also, the spectral ratio may not be similar for relatively far away locations during a particular event as observed at Verem and Kavaratti during E1 (Fig. 8a and $b$ ).

It is possible to use the transfer function between atmospheric pressure and sea level estimated for one event to predict sea-level oscillations for another event if there exists close similarities among these two events. For example, Monserrat et al. (1998) used this approach because of similarities in the atmospheric events (in particular, approximately the same propagation direction and phase speed), which generate strong seiches. In such cases, it could be expected that the transfer function would also be almost the same. In the present case, events E1 and E3 were significantly different: the respective cyclones "Yemnin" and "Phyan" had different directions, phase speed and other characteristics. Also, while the "eye" of Yemnin traversed over the land, that of Phyan traversed over the Arabian Sea. It is natural to assume that the transfer functions (atmosphere/ocean) for these two events would also have been probably different. However, the extent of the difference is not known. Thus, it would be interesting to compare the spectra (both sea-level and atmospheric pressure oscillations) pertaining to these two events and estimate the event/background ratio for each event.

Following Monserrat et al. (1998) in the use of the transfer function obtained for one event to reproduce the sea level spectra for the other events based on the coastal atmospheric pressure spectra, it can be inferred that:

$S_{\text {est }}^{Y}(\omega)=S_{\mathrm{B}}^{Y}(\omega)+T^{P}(\omega) \times W^{Y}(\omega) \times P_{\mathrm{C}}^{Y}$,

where the superscripts $Y$ and $P$ denote the events at Verem during events $\mathrm{E} 1$ and $\mathrm{E} 3$, respectively, and $W^{Y}(\omega)=\frac{S_{\mathrm{B}}^{Y}(\omega)}{E_{\mathrm{B}}(\omega)}$. Using Eq. (9), we computed the sea-level spectra during E1 using the atmospheric pressure spectra and the transfer function for E3. The agreement between the estimated (red) and observed (black) spectra (Fig. 8d) is quite promising up to periods $<45 \mathrm{~min}$. The major spectral peaks at time period $\sim 45.7,38.8,27.2$ and 13.1 min (even though lower energy) are well represented, because they are mainly due to the influence of local topography. Except for a narrow band near time period $80 \mathrm{~min}$, the computed SLR spectra for event E1 is found to be in good agreement with the measured spectrum for this event.

The power spectra of the atmospheric pressure anomaly at Verem during different events are shown in Fig. 7. The power spectrum of atmospheric pressure during E1 at Verem provides no enhancement in energies for frequencies higher than $0.0125 \mathrm{cpm}$ (period $<80 \mathrm{~min}$ ) as seen in Fig. 7a. However, during E3 at Verem, few spectral peaks are observed at time periods 142.8 and $75.2 \mathrm{~min}$ (Fig. 7c). The high-pass filtered air pressure (cutoff period $<120 \mathrm{~min}$ ) does not exceed $0.4 \mathrm{mb}$. However, during "E1", high frequency sea-level oscillations with peak amplitude $\sim 18 \mathrm{~cm}$ (Fig. 5a) is observed, when the lowest pressure monitored by IMD was on Julian days 173.5 and 174 (22 and 23 June) 2007 and the cyclone track was closest to the measurement site on 23 June 2007 (Fig. 1a). The estimated gain (ratio of sea level and atmospheric pressure) is $\sim 45 \mathrm{~cm} \mathrm{mb}^{-1}$, which is very high and, therefore, the atmospheric pressure alone may not be the cause for these oscillations. Even during the extreme events, the observed dynamical multiplication of the static barometer ("inverted barometer $=1 \mathrm{~cm} \mathrm{mb}^{-1}$ ") response is usually less than 5.0 (Hibiya and Kajiura, 1982; Vilibic et al., 2004) due to the controlling effects of friction, diffusivity and Coriolis forces. However, in some specific conditions of coastal topography (e.g., funnel shaped basins), bays with large amplification factor, energy content and direction of disturbance may produce high waves of several metres; $\sim 6 \mathrm{~m}$ in the Adriatic Sea (Orlić, 1980) and $\sim 4 \mathrm{~m}$ at Balearic Island and Nagasaki bay (Hibiya and Kajiura, 1982; Rabinovich and Monserrat, 1998).

Such anomalous gain may be due to harbour resonance. The most common factors that initiate such oscillations are atmospheric processes and nonlinear interaction of wind waves and swell. It involves first the generation of long waves in the open ocean and these waves then amplify over the shelf and near the coast. Due to the "harbour resonance", the arriving waves additionally amplify inside the corresponding bay, thereby generating intense seiches, and sometimes even destructive meteorological tsunamis. During resonance, the atmospheric disturbance propagating over the ocean surface is able to generate significant long-ocean waves by continuously pumping energy into these waves with different possibilities (refer Rabinovich et al., 2009 and related references therein) such as:

- "Proudman resonance" (Proudman, 1929), when $U=c$, i.e., the atmospheric disturbance speed $(U)$ is equal to the speed of long-ocean waves $(c=\sqrt{g h})$.

- "Greenspan resonance", (Greenspan, 1956), when $U_{l}=$ $c_{j}$, i.e., the alongshore component of the atmospheric disturbance velocity $\left(U_{l}\right)$ equals the phase speed speed $c_{j}$ of the $j$-th mode of edge waves. 
- "Shelf resonance", when the atmospheric disturbances and the associated atmospherically generated ocean waves have periods and/or wavelengths equal to the resonant period and or wavelength of the shelf region.

In the case of E1 during Yemnin, the "eye" of the disturbance in the near vicinity of the study region moved over land at a speed of $\sim 38 \mathrm{~km} \mathrm{~h}^{-1}$ and oriented $\sim 290^{\circ}$ (www.imd. gov.in) with respect to north. We suspect that the observed oscillations during E1 could be related to the forced resonant oscillation triggered in front of the estuary, by air pressure variations and wind stress, which then propagated inward into the estuary. Also, as reported in a study by Candela et al. (1999), sea-level measurements in the open sea and inside the port indicated high coherence for the bands between 25 and $40 \mathrm{cpd}$ (i.e., $36-57.6 \mathrm{~min}$ ). In contrast, at periods shorter than $35 \mathrm{~min}$ the coherence between the two records dropped significantly, indicating that these oscillations are due to local topography. In contrast to the $\pm 18 \mathrm{~cm}$ SLR oscillations observed at Verem during E1, those at Verem during E3 and Kavaratti Island lagoon during E1 are within $\sim 10 \mathrm{~cm}$. This difference could be reasoned as (Rabinovich and Monserrat, 1996): "Just as not every large underwater earthquake excites a tsunami, so even strong typhoons or atmospheric pressure jumps do not always generate destructive long waves. Both geophysical tsunamis and meteorological tsunamis are relatively infrequent events. Some specific resonance conditions are apparently necessary to generate noticeable meteorological tsunamis".

\subsection{Observed pre- and post-earthquake enhanced seawater temperature oscillations at Verem}

An interesting observation pertaining to the event E2 at Verem station near the mouth of the Mandovi estuary is that approximately 3 days prior to the 12 September 2007 Sumatra earthquake, the water temperature at this station started exhibiting a distinctly stronger semidiurnal oscillation and these well-defined oscillations continued to be manifested for a week after the earthquake. Whereas the water temperature swing during the preceding normal days was weak $\left(\sim 1.5^{\circ} \mathrm{C}\right)$, a much larger temperature swing $\left(\sim 3.5^{\circ} \mathrm{C}\right)$ is clearly seen in the period beginning $\sim 3$ days prior to the 12 September 2007 Sumatra earthquake (Fig. 3c). We also notice a relatively larger variance $\left(\sim 17.9^{\circ} \mathrm{C}^{2}\right)$ during the period of enhanced temperature swing in contrast to a lesser variance $\left(\sim 12^{\circ} \mathrm{C}^{2}\right)$ during the preceding normal days of lesser temperature swing.

Based on available information, we attempt to provide an explanation for the pre-earthquake water temperature oscillations observed at the Verem station. Earthquakes (i.e., ruptures within the earth caused by stress) are associated with the release of strained energy that has been building over many years. It is an accepted fact that a few days before a major earthquake occurs, when the plates begin to crack, a variety of signals (known as earthquake precursors) representing land, ocean, atmosphere and ionospheric anomalies begin to emanate from the preparation zone of the earthquake (see Joseph, 2011). The occurrence of a strong submarine earthquake entails intense ocean-floor oscillations in a rather large area during a prolonged period of time. Based on field measurements obtained from the JAMSTEC deepsea $(\sim 7500 \mathrm{~m}$ depth) underwater observatory (Hirata et al., 2002) during the 2003 Tokachi-Oki tsunamigenic earthquake as well as a 3-D numerical model developed in the framework of linear potential theory of ideal "compressible" fluid, Nosov and Kolesov (2007) reported clear indications of the generation of depth-dependent low-frequency elastic oscillations of the seawater column and a complicated fast oscillating wave structure on the water surface in response to the elastic oscillations of the water layer. Nosov and Kolesov (2007) found that the bottom trembling associated with the cracking provides a resonant pumping of energy to the elastic oscillations of water column, in which the bottom topography plays a leading role in the formation of the elastic oscillations spectrum.

In another mechanism, seafloor motions generate short acoustic waves in the water medium, in which intense pressure jump behind the acoustic wave-front results in the propagation of these waves from the seafloor toward the sea surface. The nonlinear effects accompanying the wave-front motion result in the transport of liquid particles from the seafloor to the sea surface - a process known as "acoustic wind" (Ostrovskii and Papilova, 1974). The just-mentioned vertical oscillations of the seawater column extending from the seafloor up to the sea surface transports the cooled water at the ocean depths to the subsurface and surface layers of the ocean. Such seismically-induced water-mass transport in the upward direction (like in a different kind of upwelling process well known in physical oceanography) results in the appearance of water-temperature anomalies in the zones of submarine earthquakes. The cooled water mass can then get transported to distant locations by several oceanographic and meteorological forcing. The vertical transport of nutrient-rich water, induced by this upwelling process, has been found to give rise to a significant increase of chlorophyll concentrations in the upper layers of the sea surface "prior" to the earthquake events (Singh et al., 2006), and its spatial and temporal variability occur due to the large-scale disturbances in the oceanic circulation patterns, arising from sudden changes of thermal structure (Chaturvedi and Narain, 2003).

Sea-surface water temperature drop observed in the coastal and open sea water bodies prior to submarine earthquakes have been measured using orbiting satellite-borne remote sensors. In such cases, although measurements are obtained over a considerably large area, the temporal resolution is rather poor. Thus, a clear description of the evolution and the fine-scale temporal variability of the seasurface temperature are often not available. However, these 
measurements yield the average feature of the temperature variability. For example, during the 1996 earthquake event off Japan's coast, the ocean surface water temperature deviation over a zone of horizontal dimension of $\sim 500 \mathrm{~km}$ was minus $4-5^{\circ} \mathrm{C}$ and the anomaly lifetime exceeded two days (Levin et al., 2006). Such seismically induced sea-surface water temperature drops were recorded also in the Sea of Okhotsk and in the Black Sea (Nosov, 1998; Zaichenko et al., 2002).

In the present study, time-series water temperature measurements (sampled at a frequency of $2 \mathrm{~Hz}$ and averaged over $5 \mathrm{~min}$ ) were obtained from Verem station at the Mandovi estuary at $5 \mathrm{~min}$ interval from a depth of $\sim 1 \mathrm{~m}$ below chart datum level. It is seen from Fig. 3b that a distinctly clear water temperature oscillations at Verem started $\sim 3$ days before the Sumatra earthquake (12 September 2007). The water temperature anomaly (over a 40-day period covering the event) is generally negative (Fig. 3d), indicating an effective drop in temperature during this period. The power spectral density (PSD, Fig. 3e) of water temperature oscillations during a fortnight covering the event (Julian days 252-268) indicate the highest PSD for the semidiurnal constituent $(\sim 12 \mathrm{~h})$ and considerably smaller PSD $(\sim 50 \%)$ for the diurnal constituent $(\sim 24 \mathrm{~h})$. The corresponding PSDs for the water temperature oscillations during approximately 10-days temporal segments preceding (Julian days 240-251) and succeeding (Julian days 269-278) the event segment (Julian days 252268) were negligibly small. This indicates the selective enhancement of water temperature oscillations during the event segment. From Fig. 9, it is evident that the water temperature oscillation during the event segment is clearly semidiurnal, with its negative swing occurring during flood tide and positive swing during ebb tide. The study region is the mouth of a tropical estuary. During the flood tide phase, the seismically cooled offshore sea-surface water is progressively transported into the estuary. This causes the observed enhanced negative swing of the water temperature oscillation during the flood tide phase in the event-segment. During ebb tide phase, the seismically unaffected (and, therefore, relatively warmer) water mass in the upper regions of the estuary is progressively discharged into the mouth of the estuary. This is responsible for the observed enhanced positive swing of the water temperature oscillation during the ebb tide phase in the event-segment. The observed insignificant swing of the water temperature oscillations preceding and succeeding the seismic event period arises from the absence of sea surface water cooling. This discussion hints that the observed enhanced negative and positive water temperature swings occurring during flood and ebb tide phases, respectively, could be a tropical estuarine phenomenon, which could be absent in open seas and coastal waters where only a lowering of water temperature would be manifested during pre- and postearthquake periods. The observed enhanced water temperature oscillations may be absent also at inherently cold estuaries.

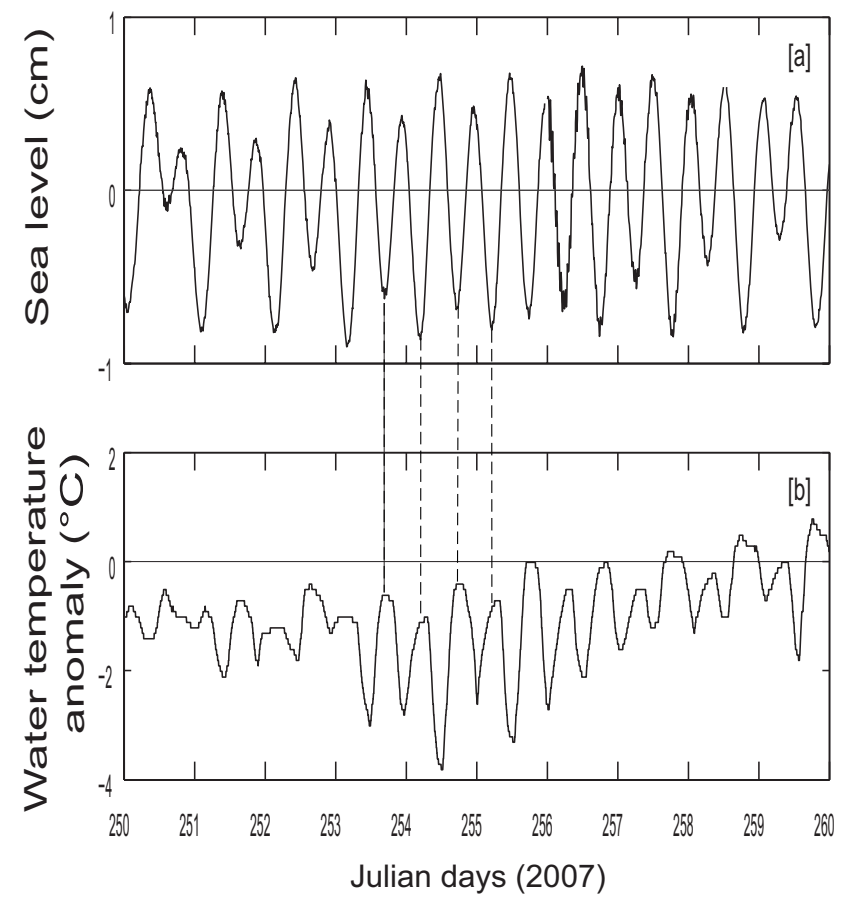

Fig. 9. Sea-water parameters observed at Verem, Goa during event E2 of 12 September 2007 due to Sumatra earthquake $\left(M_{\mathrm{W}}=\right.$ 8.4). (a) Sea level $(\mathrm{cm})$ and (b) measured water temperature anomaly $\left({ }^{\circ} \mathrm{C}\right)$.

\section{Conclusions}

This study is an attempt to investigate the meteorologically and seismically induced water level and water temperature oscillations at a station (Verem) located near the mouth of a tropical estuary (Mandovi) on the west coast of India. In particular, we examine the response of sea level to the passage of the "eye" of the cyclonic storm "Yemnin" over land using empirical as well as theoretical approaches. The observed oscillations appear to be related to the large atmospheric disturbance and associated wind stress. These sea level oscillations are similar in frequency content as earlier reported by us in the case of the September 2007 Sumatra tsunami signals observed at this station (Prabhudesai et al., 2008). In particular, the water-level oscillations found at Verem during Yemnin appear to be the result of harbour resonance. Except for a narrow band near time period $80 \mathrm{~min}$, the computed SLR spectra for event E1 was found to be in good agreement with the measured spectrum for this event. This suggests that the structure of sea-level spectra near the coast, although related to the local topography is also significantly affected by the external forcing. The disastrous geophysical tsunamis are normally generated by earthquakes, which are relatively infrequent. However, strong atmospheric disturbances of various types (passing fronts, squalls and trains of atmospheric waves) are common and needs attention in this 
region in future studies using higher sampling frequencies ( 1 min interval) and instrumentations deployed off the coast.

A distinctly enhanced pre- and post-earthquake (12 September 2007 Sumatra earthquake) seawater temperature oscillations observed in the tropical estuary of the present study provides an indication that routine monitoring of fine temporal resolution seawater temperature measurements from tropical estuaries may provide early information about impending coastal earthquakes. This study also reveals the importance of incorporating time-series seawater temperature measurements with sea-level stations located at tropical estuarine sites. We propose that real-time reporting systems measuring this probable earthquake precursor could be implemented in future earthquake/tsunami early-warning systems.

Acknowledgements. The authors acknowledge the support of the Indian Naval Office at Verem, Goa for providing a safe and secured site for sea-level measurements. They are grateful to A. Shirgoankar for his consistent support in keeping the systems operational. Figures provided in this work were prepared by L. Nadaf. They also acknowledge the support and encouragement of the Director of CSIR-NIO, Goa, in carrying out this work. The authors are indebted to Alexander B. Rabinovich (Russian Academy of Sciences) for providing many useful suggestions, which helped improving the quality of this work. They are also grateful to N. R. Dalezios and T. Karambas for providing encouraging review. This is NIO contribution number: 5109.

Edited by: N. R. Dalezios

Reviewed by: T. Karambas and A. B. Rabinovich

\section{References}

Bell, C., Vassie, J. M., and Woodworth, P. L.: Tidal Analysis Software Kit 2000 (TASK-2000), POL/PSMSL Permanent Service for Mean Sea Level, Proudman Oceanographic Laboratory, UK, 2000.

Candela, J., Mazzola, S., Sammari, C., Limeburner, R., Lozano, C. J., and Patti, B.: The "Mad Sea" Phenomenon in the Strait of Sicily, J. Phys. Oceanogr., 29, 2210-2231, 1999.

Chaturvedi, N. and Narain, A.: Chlorophyll distribution pattern in the Arabian Sea: seasonal and regional variability, as observed from SeaWiFS data, Int. J. Remote Sens., 24, 511-518, 2003.

Fujita, T.: Results of detailed synoptic studies of squall lines, Tellus, 7, 405-436, 1955.

Greenspan, H. P.: The generation of edge waves by moving pressure disturbances, J. Fluid Mech., 6, 574-592, 1956.

Hibiya, T. and Kajiura, K.: Origin of the Abiki phenomenon (a kind of seiche) in Nagasaki Bay, J. Oceanogr. Soc. Jpn., 38, 172-182, 1982.

Hirata, K., Aoyagi, M., Mikada, H., Kawaguchi, K., Kaiho, Y., Iwase, R., Morita, S., Fujisawa, I., Sugioka, H., Mitsuzawa, K., Suyehiro, K., Kinoshita, H., and Fujiwara, N.: Real-time geophysical measurements on the deep seafloor using submarine cable in the southern Kurile subduction zone, IEEE J. Oceanic Eng., 27, 170-181, 2002.
Joseph, A.: Tsunamis: Detection, monitoring, and early-warning technologies, Elsevier/Academic Press, New York, 448 pp., (doi:10.1016/B978-0-12-385053-9.10001-8), ISBN 978-0-12385053-9, 2011.

Joseph, A., Prabhudesai, R. G., Mehra, P., Sanil Kumar, V., Radhakrishnan, K. V., Vijaykumar, K., Ashok Kumar, K., Agarwadekar, Y., Bhat, U. G., Luis, R., Rivankar, P., and Viegas, B.: Response of west Indian coastal regions and Kavaratti lagoon to the November-2009 tropical cyclone Phyan, Nat. Hazards, 57, 293-312, doi:10.1007/s11069-010-9613-7, 2011.

Kulikov, E. A., Rabinovich, A. B., Spirin, A. I., Poole, S. L., and Soloviev, S. L.: Measurement of tsunamis in the open ocean, Mar. Geodesy, 6, 311-329, 1983.

Levin, B. V., Likhacheva, O. N., and Uraevskii, E. P.: Variability in the thermal structure of ocean waters in periods of strong seismic activity, Izvestiya, Atmos. Ocean. Phys., 42, 653-657, 2006.

Mehra, P., Prabhudesai, R. G., Joseph, A., Vijaykumar, K., Dabholkar, N., Prabhudesai, S., Nagvekar, S., and Agarvadekar, Y.: Endurance and stability of some surface meteorological sensors under land- and ship-based operating environments, Proceedings of the National Symposium on Ocean Electronics, SYMPOL, 15-16 December 2005, 257-264, 2005.

Mehra, P., Joseph, A., Prabhudesai, R. G., Viajykumar, K., Sundar, D., and Tengali, S.: On the usability of "compensated temperature" output of Honeywell PPTR sensor for coastal oceanographic and limnological studies, Proceedings of the International Conference: Oceans'08 MTS/IEEE-Kobe-TechnoOcean'08 (OTO’08) from 8-11 April 2008, 2008.

Monserrat, S. and Thorpe, A. J.: Gravity wave observations using an array of microbarographs in the Balearic Islands, Quart. J. Roy. Meteor. Soc., 118, 259-282, 1992.

Monserrat, S., Rabinovich, A. B., and Casa, B.: On the reconstruction of the function for atmospherically generated seiches, Geophys. Res. Lett., 25, 2197-2200, 1998.

Monserrat, S., Vilibić, I., and Rabinovich, A. B.: Meteotsunamis: atmospherically induced destructive ocean waves in the tsunami frequency band, Nat. Hazards Earth Syst. Sci., 6, 1035-1051, doi:10.5194/nhess-6-1035-2006, 2006.

Nosov, M. A: Effect of underwater earthquakes on the stratified ocean, Vestn. Mosk. Univ., Ser. 3, Fiz., Astron, 4, 23-27, 1998.

Nosov, M. A. and Kolesov, S. V.: Elastic oscillations of water column in the 2003 Tokachi-oki tsunami source: in-situ measurements and 3-D numerical modelling, Nat. Hazards Earth Syst. Sci., 7, 243-249, doi:10.5194/nhess-7-243-2007, 2007.

Orlić, M.: About the possible occurrence of the Proudman resonance in the Adriatic, Thalassia Jugoslavica 16, 79-88, 1980.

Ostrovskii, L. A, and Papilova, I. A.: On a nonlinear acoustic wind, Akust. Zh., 20, 79-86, 1974.

Pattiaratchi, B. C. and Wijeratne Sarath, E. M.: Tide Gauge Observations of 2004-2007 Indian Ocean Tsunami from Sri Lanka and Western Australia, Pure Appl. Geophys., 166, 233-258, 2009.

Prabhudesai, R. G., Joseph, A., Agarvadekar, Y., Dabholkar, N., Mehra, P., Gouveia, A., Tengali, S., Vijaykumar, K., and Parab, A.: Development and implementation of cellular-based real-time reporting and Internet accessible coastal sea level gauge - A vital tool for monitoring storm surge and tsunami, Current Science, 90, 1413-1418, 2006.

Prabhudesai, R. G., Joseph, A., Mehra, P., Agarvadekar, A., Tengali, A., and Vijaykumar, K.: Cellular-based and Internet- 
enabled real-time reporting of the tsunami at Goa and Kavaratti Island due to $\mathrm{Mw} 8.4$ earthquake in Sumatra on 12 September 2007, Current Science, 90, 10 May 2008, 1151-1157, 2008.

Prabhudesai, R. G., Joseph, A., Agarwadekar, Y., Mehra, P., Vijaykumar, K., and Luis, R.: Integrated Coastal Observation Network (ICON) for real-time monitoring of sea-level, sea-state, and surface-meteorological data, OCEANS' 10 - IEEE Seattle Technical Conference; September 2010; IEEE, 9 pp, 2010.

Proudman, J.: The effects on the sea of changes in atmospheric pressure, Geophys, Suppl. Mon. Notices R. Astr. Soc., 2, 197209, 1929.

Rabinovich, A. B.: Spectral analysis tsunami waves: Separation of source and topography effects, J. Geophys Res., 102, 1266312676, doi:10.1029/97/JC00479, 1997.

Rabinovich, A. B.: Seiches and Harbor Oscillations, Chapter 9, Handbook of Coastal and Ocean Engineering, edited by: Kim, Y. C., World Scientific Publ., Singapore, 2009.

Rabinovich, A. B. and Monserrat S.: Meteorological Tsunamis near the Balearic and Kuril Islands: Descriptive and statistical analysis, Nat. Hazards, 13, 55-90, 1996.

Rabinovich, A. B. and Monserrat, S.: Generation of meteorological tsunamis (large amplitude seiches) near the Balearic and Kuril Islands, Nat. Hazards, 18, 27-55, 1998.
Shetye, S. R., DileepKumar, M., and Shankar, D.: The Mandovi and Zuari estuaries, National Institute of Oceanography, Dona Paula, Goa, India, 2007, xiii+, 145 pp., 2007.

Singh, R. P., Dey, S., Bhoi, S., Sun, D., Cervone, G., and Kafatos, M.: Anomalous increase of chlorophyll concentrations associated with earthquakes, Adv. Space Res., 37, 671-680, 2006.

Sundar, D. and Shetye, S. R.: Tides in the Mandovi and Zuari estuaries, Goa, west coast of India, J. Earth Syst. Sci., 114, October 2005, 493-503, 2005.

Vijaykumar, K., Joseph, A., Prabhudesai, R. G., Prabhudesai, S., Nagvekar, S., and Damodaran, V.: Performance evaluation of Honeywell silicon piezoresistive pressure transducers for oceanographic and limnological measurements, J. Atmos. Ocean. Technol., 22, 1933-1939, 2005.

Vilibić, I., Domijan, N., Orlić, M., Leder, N., and Pasarić, M.: Resonant coupling of a traveling air-pressure disturbance with the east Adriatic coastal waters, J. Geophys. Res., 109, C10001, 10.1029/2004JC002279, 2004.

Zaichenko, M. Yu., Levin, B. V., Pavlov, V. P., and Yakubenko, V. G.: Cooling effect of the Black Sea active layer recorded after the earthquake, Izvestiya, Atmos. Oceanic Phys., 38, 695-699, 2002 . 